\title{
Profile of the health and safety coordinator in civil engineering works: the Spanish case
}

\author{
María José Rodríguez-Largacha (Main and Corresponding Author) \\ Civil Engineering Department, School of Architecture and Engineering \\ Universidad Europea de Madrid (Spain) \\ mariajose.rodriguez@universidadeuropea.es
}

\section{Gonzalo Fernández-Sánchez}

Civil Engineering Department, School of Architecture and Engineering

Universidad Europea de Madrid (Spain)

gonzalo.fernandez@ext.universidadeuropea.es

\section{Jesús Esteban}

Civil Engineering Department, School of Architecture and Engineering Universidad Europea de Madrid (Spain)

jesus.esteban@universidadeuropea.es

\author{
Manuscript Code: 1369 \\ Date of Acceptance/Reception: 03.12.2019/05.03.2019 \\ DOI: $10.7764 /$ RDLC.18.3.513
}

\begin{abstract}
The profile and function of the health and safety coordinator in civil engineering works has till now received insufficient attention. This paper first analyzed all public contracts between 2008 to 2016 in Spain related to health and safety. We then proceeded to assess a case study of a company focused on health and safety coordination in the period 2012 to 2015 and the results of a survey of the views of different stakeholders. We then used the knowledge acquired, objective results, and lessons learned to develop recommendations related to the profile, main functions, and best practices for the performance of health and safety coordination.
\end{abstract}

Keywords: Health and safety coordinator, construction, civil engineering, health and safety, competencies and functions.

Introduction

The construction sector has always occupied a leading role in the economic environment, but it is also a leader regarding the number of accidents (López-Arquillos \& Rubio-Romero, 2015). In the European Union, almost $21 \%$ of fatal accidents in 2014 occurred in the construction sector (Eurostat, 2016). In countries like Spain, the incidence rate of accidents at work in the construction sector has been decreasing in recent years, but the accident rate is still double compared to all other activities (INSHT, 2010).

In this context, it appears that the concurrence of companies is a determining factor in the accident rate of the sector (Vicente, 2008; Arévalo, 2003; García, 2011). Thus, the European Directive 92/57/EEC itself recognizes this circumstance by identifying the construction works as a particular sector of concern. It establishes mechanisms such as the health and safety coordinator, whose role it is to alleviate this concurrence factor. However, there are significant misperceptions regarding their appointment, competencies, functions, tools, and procedures to carry out their tasks (Aires et al., 2010). The Security Commission of the European Union establishes both the appointment and responsibilities of the coordinators as its main concern, among other priorities (CSUE, 2008).

The position of the coordinator is defined as a "competent technician," but this "competence" is not specifically defined. Hence, there is research that analyzes the training and knowledge that a health and safety coordinator should have (Ros, 2012). The INSHT (National Institute of Occupational Safety and Health) defines this role as a person who has both academic and professional qualifications as well as knowledge of construction and labor risk prevention relevant to the functions they must fulfill. INSHT further noted that those who oversee and manage construction operations should also be able to coordinate health and safety. Vicente (2008) maintained that even if a person has the competency to both manage and coordinate health and safety, those roles and responsibilities should not be carried out by the same professional.

Regarding training in labor risk prevention in the Spanish sector, it is suggested that the program should be a 200-hour course, adapted to the construction sector and including some of the content suggested in the INSHT Technical Guide. 
This content has been developed as the result of the construction working group of the National Commission for Health and Safety at Work (CNSST, 2001). Other authors, such as Vicente (2008), Ros et al. (2013) or Lozano (2015) maintained that this training should be integrated into the curriculum of corresponding academic degrees.

The legal function of a health and safety coordinator in Europe is the coordination of general principles of prevention and safety. This includes making technical and organizational decisions to plan different operations simultaneously or successively and estimating the time required for execution. The coordination of operational activities also includes ensuring:

- $\quad$ all actors apply the principles of preventive action in a coherent and responsible way,

- approval of the health and safety plan prepared by the contractor and any modifications,

- organization and coordination of business activities,

- coordination of control actions and functions for the correct application of operational methods,

- adoption of the necessary measures to provide site access only to appropriate people,

- $\quad$ provide warnings of non-compliance concerning safety measures, even if that includes stopping construction (or parts at serious or imminent risk).

However, with all these responsibilities and obligations, the extent to which the scope, commitment or necessary activities of the health and safety coordinator are deemed mandatory remains unclear. It is even described as "difficult to specify" (INSHT), and it will depend on factors such as work volume, duration, characteristics, the conduct of specifically risky operations, and others.

The objective of this study is to analyze almost 20 years of the implementation of health and safety coordination in Spain (RD 1627/97 in application to the European Directive 92/57 / CEE and its various updates or developments such as RD 171/2004). Furthermore, the profile and functions of such profile in civil engineering projects in Spain. Thus, the following secondary objectives are proposed:

- To develop a profile of health and safety coordinator.

- To analyze the functions and tools used by health and safety coordinator.

- $\quad$ To propose best practices for the performance of the health and safety coordinator.

In Spain, the appointment of a health and safety coordinator during the execution of construction is mandatory, provided that the work involves more than one company. This even includes a company and self-employed workers working independently of other factors such as the type of work or whether a project exists.

State of the Art

The available tools and instruments for the health and safety coordinator to perform their functions during the execution of the operations are:

- Meetings to plan and coordinate between companies, with documented evidence. Also, other communication systems between concurrent companies, periodic risk assessments, preventive resources, etc. (Vicente, 2008). Poor planning is one of the factors that greatly undermine accident and health prevention (CSUE, 2008).

- Visits to the operational location, where the health and safety coordinator should not be permanently on-site but ensure that the plan is being fulfilled.

- An incident book to control and monitor the health and safety plan. The contractor and the workers' representatives must be notified of each entry.

- The ability to halt operations when health and safety measures are not fulfilled, leaving an entry in the incident book for serious and imminent health and safety risk for workers.

- The book of subcontracting where each entry by the contractor must inform the health and safety coordinator to allow them to coordinate and fulfil their duties.

Thus, the health and safety coordinator participates in technical and organizational decisions, documents the approval of the health and safety plan and its annexes, provides the necessary information so that everyone can perform their functions in cooperation, and validates and supervises the procedure proposed by the contractor for the control of access to the project. The management of responsibilities and action methodology, such as visits to the site in the event of an accident, are essential for the coordinators (Ros et al., 2012). In this sense, great communication skills, teamwork, and efficiency are necessary (Vesmand, 2011). 
There are many publications and studies related to general labor risk prevention, quality, environmental and health and safety rules and regulations (Koehn \& Datta, 2003). However, when the study focuses on health and safety coordination in construction works, something paradoxical happens. The actual presence of a coordinator during the project phase is nominal (Arevalo, 2003) but in many cases, mandatory during the construction phase. Nonetheless, this model is inverted in the field of research: it is in the project phase where there are more publications related to the health and safety coordinator (Esteban, 2011; Esteban et al., 2013; Arevalo, 2013; Gálvez, 2013). During the execution of the construction work, the studies focused on the health and safety coordinator are practically nonexistent, and completely absent if we focus on civil engineering works. Logically, these studies are based on Lorent (1989) about the need to act preventively from the design phase. However, there are some approaches (e.g., Ros, 2013) that explore the knowledge the health and safety coordinator should have during the execution of construction operations with two key competencies: commitment to the project and communication. According to Lozano (2015), the involvement of the coordinator in the building stage contributes significantly to a reduction in the accident rate. He considers it necessary to update and consolidate the competencies and management tools as well as academic training, experience, and other issues to enhance professionalization. Importance of training at the construction work is highlighted by different authors (e.g., Fuentes del Burgo \& Navarro-Astor, 2013a, b).

Some studies focused on specific risks in the construction stage for specific tunnel works and safety measures implementation (Mishra et al., 2019), off-road machinery (e.g., Edwards \& Holt, 2014) or proposals to be applied in mega construction projects (Maiti \& Choi, 2019) already exist but not with a holistic health and safety construction approach. It is precisely for this reason that this study has focused on the role of the health and safety coordinator in civil engineering operations. This article aims to address a gap in the existing scientific and technical literature using the Spanish case as a pilot study.

Methodology

To achieve our study objectives, we reviewed the literature, information, and documentation through three synergistic techniques:

1. The analysis of all publicly published contracts during the period 2007 to 2015 in Spain related to health and safety coordination for civil engineering operations. Here, the requirements and role of the coordinator are analyzed, establishing relationships between correlational variables instead of experimental analysis. In total, there are 326 case studies published at a national, regional and local level. Control lists have been formulated to allow for the identification and analysis of data in a homogeneous and objective way.

2. The assessment of a single case study between 2012 and 2015. The selected case, Incope, is a company which has around 200 civil engineering projects per year. This company was created in 2003 joining the market for the prevention of occupational hazards within the specific sector of health and safety coordination in construction works. Incope is recognized as one of the most prestigious companies in the sector at the national level currently holding the presidency of the national association of health and safety coordination companies (ECSYS). The company has 31 technicians, all of whom are engineers and architects with extensive experience in the sector and spread across different Spanish geographies. Incope is a small company (according to the definition of Small and Medium Enterprises in Europe 651/2014) with fewer than 50 workers and a volume of less than 10 million euros in the specialized health and safety coordination business. Incope focuses on civil engineering projects at the national level. In 2012, all employees were notified about the study and the company management committed to implementing the information collection system designed for this research project. For this case, data were collected during these years by checklists to identify and analyze the information in a homogeneous and objective way, which makes these results comparable to previous ones.

3. Finally, a survey was conducted through the association of health and safety coordination professionals ECSYS (Association of Health and Safety Coordination Companies), which is the largest professional platform in the sector in Spain. This questionnaire sought to discover:

a. The degree of knowledge respondents had about health and safety coordinators, their obligations and responsibilities

b. The profile of a good coordinator in terms of their training and experience

c. The obligations of the coordinator and the tasks demanded in the development of their skills

A pilot test was carried out with 30 technicians (engineers, technical architects or superiors, with a master's degree in labor risk prevention and with an average of ten years of experience of project coordination). Once the observations had been collected, they were evaluated by the management and the Secretary of ECSYS obtaining a final questionnaire of 23 questions with a total response time of 10 minutes. This was an anonymous survey which collected profile data 
but no personal data. It was launched at the end of October 2014 (through bulletins, homepage, and contacts through the 1,900 subscribers). $12 \%$ of the recipients answered the questionnaire. Descriptive statistics are used for the analysis of the results.

\section{Study of public contract documents of health and safety coordinators in construction works}

This part of the study focused on the analysis of 326 documents detailing the technical specifications for contracting specific health and safety coordination services during the execution of operations by the main public administrations in Spain. During the last decade (2008 - 2015) national, regional, and local administrations have awarded public works in Spain to the value of 51.91 million Euros. Most of the investment is in rail infrastructure (59.6\%) followed by motorways (29.16\%), and state ports with ADIF (Railway Infrastructure Administration of Spain), and DGC (General Direction of Roads of Spain) as the two main bidders for specific health and safety coordination contracts. It is true that there has been a significant reduction in new construction projects, and no recovery is expected in the coming years. Nevertheless, this will be converted into maintenance, conservation, and rehabilitation construction which will continue to require coordination of health and safety in its execution.

The following Figure 1 shows the number of documents included in the study by years, its distribution by area (local, regional and state) as well as by type of projects and infrastructure.
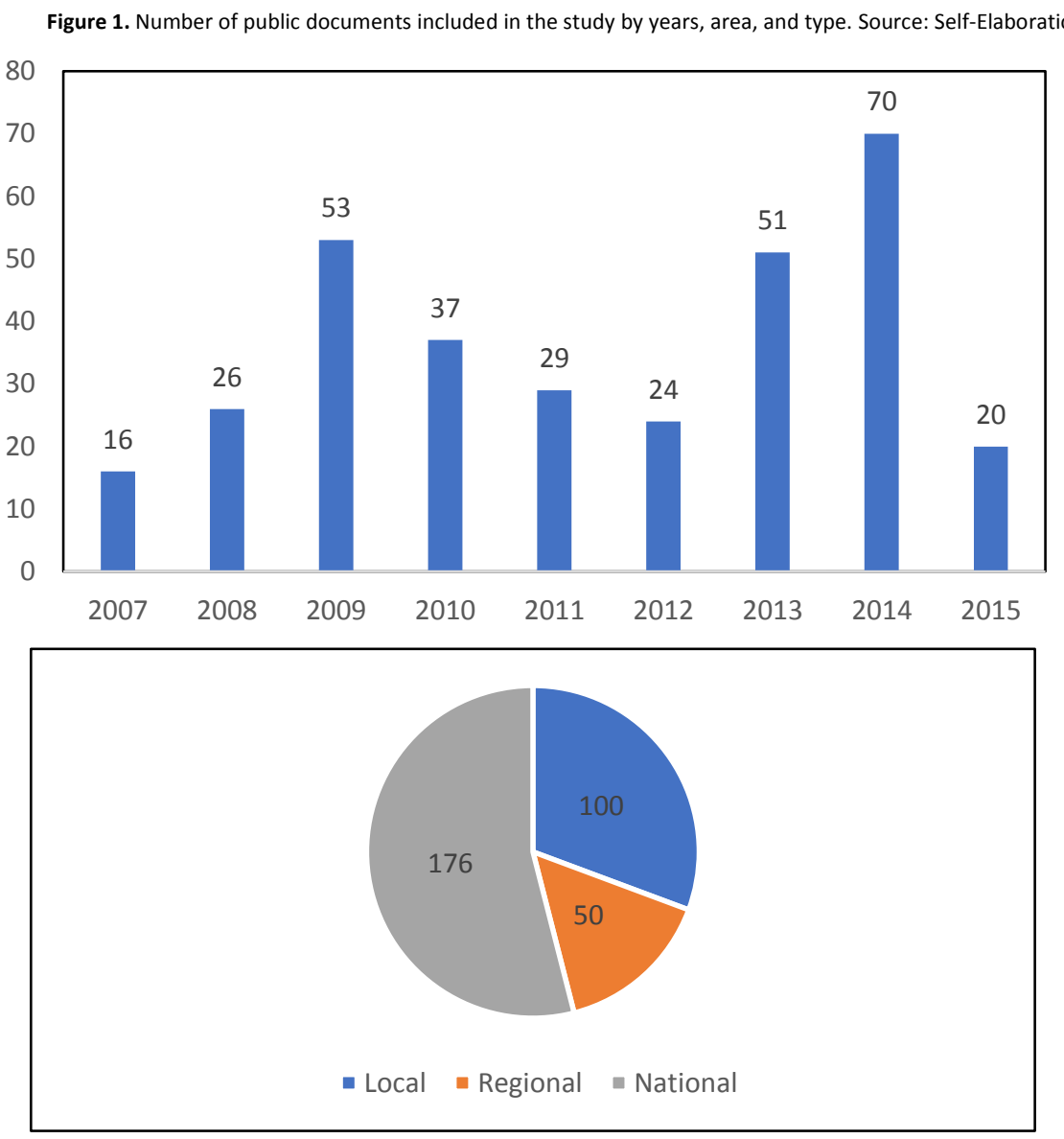


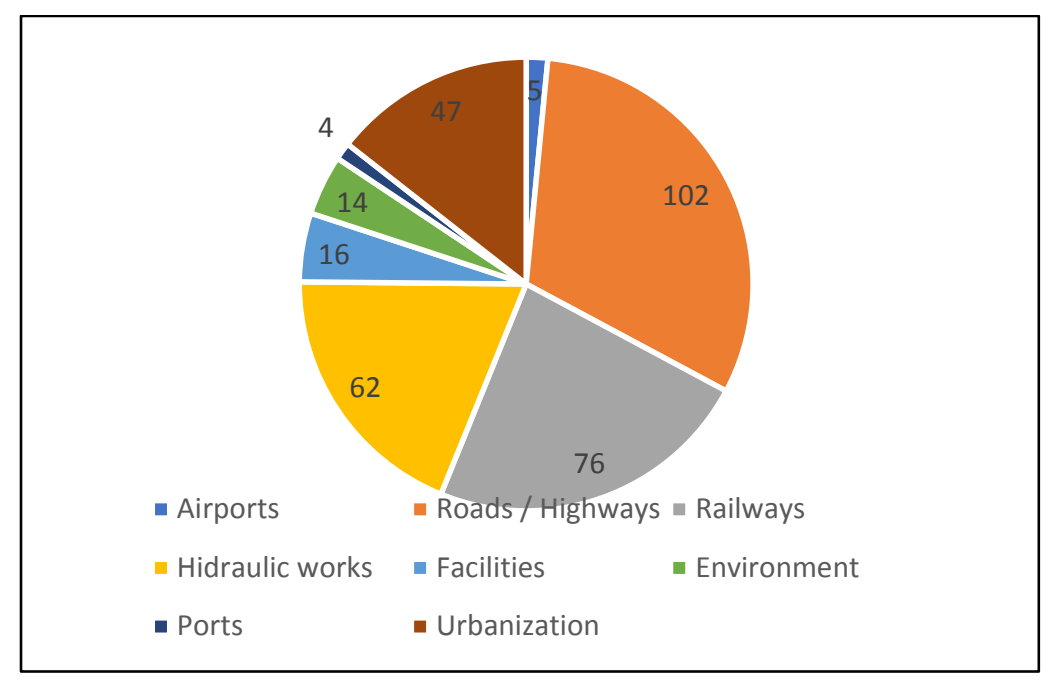

As a result of studying all the documents during the analyzed period, we conclude that the profile of the "Competent Technician" required for the role of health and safety coordinator has the following characteristics:

- University education: $35 \%$ of the analyzed documentation refers to building legislation: Academic degrees and professionals qualified to perform the function of health and safety coordinator in building works, during the preparation of the project and execution of the work, will be those related to architecture, technical architecture, engineering or technical engineering, according to their competencies and specialties. In $28 \%$ of the cases, the specialty according to the type of work is defined, whereas $22 \%$ established the need to be an engineer or technical engineer without identifying the specialty.

- Training in labor risk prevention: $70 \%$ of the analyzed documents required a degree as a technical specialist in labor risk prevention. $3 \%$ considered training as an intermediate level technician in labor risk prevention valid, and the rest were limited to saying that "they will be competent" or do not say anything at all.

- Experience: $42 \%$ required experience in coordination without specifying the specific type of construction work, compared to $58 \%$ who do specify a type. $42 \%$ asked for previous experience of up to 3 years, compared with $20 \%$ who asked for 5 years or more. $1 \%$ required official proof of activities for the coordinator, and $4 \%$ required a lawyer or legal adviser on the team.

\section{Case study of a Company specialized in coordination}

The number of operations analyzed by our case study company from 2012 to 2015 appears in the following Figure 2. The following functions carried out by health and safety coordinators were considered: tools used, number of meetings, number of document checks, number of monitoring reports, site visits, attachments to the health and safety plan requested, entries in the incident book, and a final certificate of customer satisfaction.

Figure 2. Number of civil engineering works analyzed. Source: Self-Elaboration

2012

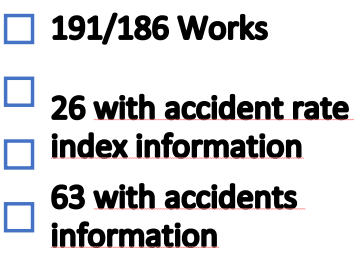

2013

\section{3/150 Works}

52 with accident rate index information 56 with accidents information
2014

2015

It is important to contextualize the incidence index of the case study within the broader Spanish context; therefore, the Spanish incidence index is included below (Figure 3). In this sense, the case study selected is considered as a great lesson learned to be assessed and applied. 


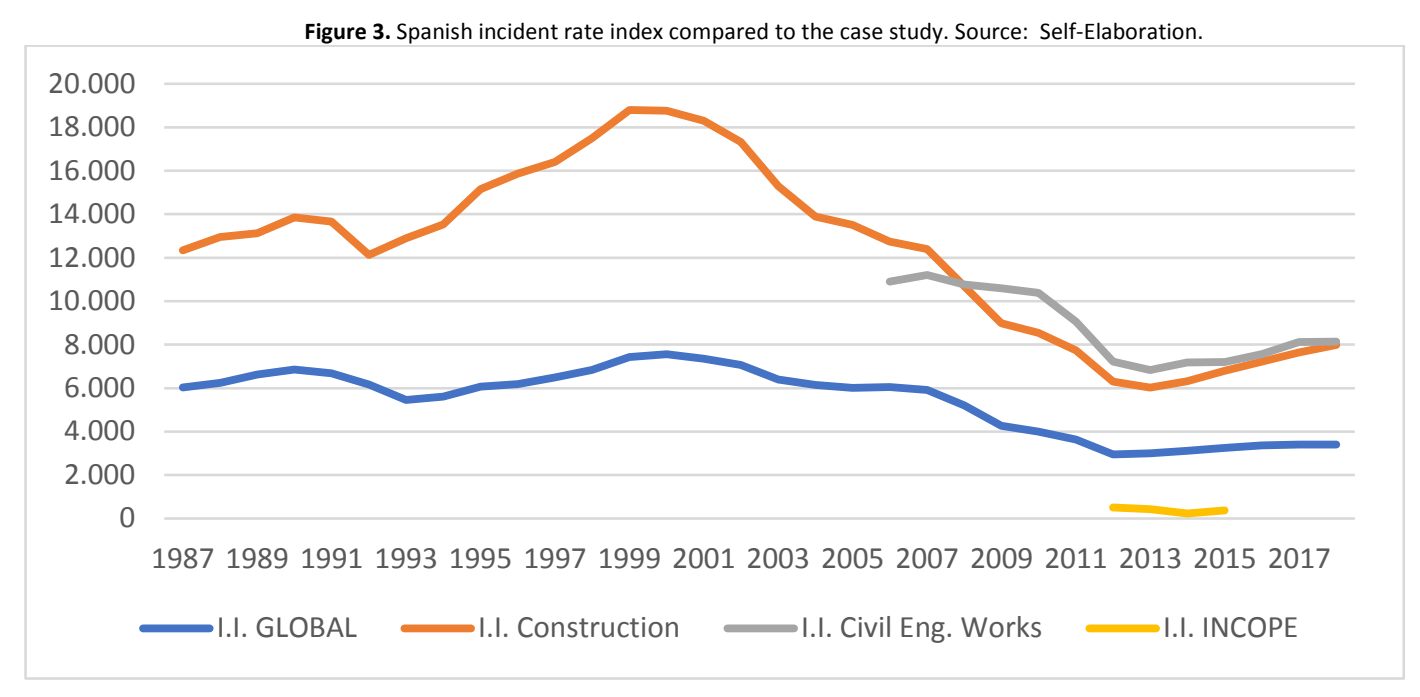

Each coordinator completes the data log of their functions and indicators on a monthly basis. The operations under analysis have been ordered by type of work, number of contractors, deadline, end of work date, project budget and health and safety budget, coordination budget and accident ratio.

The procedure followed here reduces both the quantity of files generated and the information therein by unifying the information management tables. Instead of managing one file per project, it manages a file by coordinator, which will contain information about all their projects, except those that are part of a "multi-works" contract of limited size and duration.

At the end of each semester, the quality manager is responsible for collecting and organizing all the results generated by all the technicians of the company and at the end of each year the results, obtained by this research are shared with all employees.

In turn, the number of operations under study is constantly varying, given the heterogeneity and diversity in the construction work's areas, types, and especially deadlines.

The study itself proves to be a result by becoming a tool for continuous improvement and definition of health and safety and how to improve it.

One of the main results is that extensive work by the health and safety coordinator can increase safety with their indicators and tools, but it does not necessarily decrease the accident rate. In fact, it is notable that these indicators (number of meetings, document checks, visits to work) which should be more successful the greater their number, turn out to be higher when the work gets complicated, and there are accidents. Therefore, this seems to indicate that the increase in these preventative actions are positive but not as data since there is usually an upwards trend when adverse incidents occur.

The case study has an average number of 25 technicians who act as health and safety coordinators. The profile of the aforementioned technicians responds to the academic education established by the Building Regulation Law, all being architects, technical architects, engineers or technical engineers. They had training in prevention at the technical specialist level in labor risk prevention (as per RD 39/97), with a tendency for all of them to have a master's degree in labor risk prevention and health and safety coordination as recommended by INSHT.

The functions considered relevant are those based on monitoring the health and safety plan, giving special relevance to the approval and monitoring of that plan, the coordination of different activities and the coordination of activities during the execution of the work from the point of view of preventive planning.

Coordination tools are essential in the organization of business activities as well as in the planning of previous operations. Preventive planning is thereby considered the main tool to use. 


\section{Questionnaire for interest groups of health and safety coordination}

The questionnaire consisted of 23 questions organized into five topics: data about the respondent; characteristics the profile of the health and safety coordinator should have; impact of the coordinator in accident reduction; necessary skills for every health and safety coordinator and health and safety costs. There were 235 respondents to the survey.

Of the people who answered the questionnaire, 59.2\% were engineers, technicians or technical specialists, while $23.7 \%$ were architects (technicians or specialists), 11.1\% were graduates (without identifying the specialty or engineering area in which they were carrying out their activity), and a remaining $5.1 \%$ held other degrees not directly linked to construction.

More than $50 \%$ of respondents had training in labor risk prevention at a higher-education level $(41.7 \%$ had higher education in labor risk prevention, and $19.1 \%$ had a university master's degree in labor risk prevention).

Of the respondents who reported, $95 \%$ had more than 5 experience years as a health and safety coordinator. One hundred ninety-one stated that they had experience as a health and safety coordinator in the project design stage and 223 as a health and safety coordinator in the execution stage.

There is almost unanimity (99.57\%) among respondents about the need for the health and safety coordinator to have a university-level education. On the other hand, the answers are almost 50-50 among those who think that this should be in accordance with the specialty of the work in which they will perform their functions (51.05\%) and those who do not think any specialization is necessary (48.42\%).

Significant differences came to light with regard to attitudes about training in labor risk prevention. Of the respondents, $40.5 \%$ thought they must have a high level of prevention qualification ( 600 hours), followed by $31.6 \%$ who supported a health and safety coordinator course (200 hours), and finally, 18.4\% favored a master's degree in prevention (60 ECTS).

Regarding the development of the safety coordinator's activities during work execution, the dedication, experience and processes are analyzed according to the type of work. The following can be concluded:

- $\quad$ For projects up to $100,000 €, 48 \%$ of respondents considered a workload allocation of less than $25 \%$ enough for managing health and safety at the construction work site properly, compared to $37.37 \%$ who considered that it should be higher, between $25 \%$ and $50 \%$ of their time. Seventy per cent of respondents considered it enough to make a weekly visit, compared to $15.79 \%$ who thought only occasional visits should be required. In terms of the experience required for the role, 1 to 3 years was considered sufficient for $50 \%$ of the respondents, and even less than one year for $32 \%$ of those surveyed.

- For civil engineering works valued between $100,000 €$ and $1,000,000 €, 41.05 \%$ of respondents considered that the coordinator should dedicate more than $50 \%$ of their time to the project, compared to $40.53 \%$ who considered that $25 \%$ of the working day would be enough. In addition, $53.68 \%$ considered it enough to make a weekly visit, compared to $40 \%$ who considered that the health and safety coordinator should conduct a daily visit to the site. The experience in coordination required varied between 3 to 5 years (42\%) and 1 to 3 years (39\%).

- $\quad$ For works valued at more than $1,000,000 € 49.47 \%$ of respondents believed that a complete dedication to the location was necessary, compared to $31.58 \%$ who considered that it should be more than $50 \%$ but not the whole time. In this case, some required a daily visit (39.47\%) while others felt staying on site was necessary (38.42\%). In addition, the experience required for these projects was more than 5 years for most respondents (55\%) followed by 3 to 5 years for $30 \%$.

The usual functions of the health and safety coordinators in the execution phase of the work appear in Figure 4, together with the most used and most relevant tools (Figure 5), and the personal skills and knowledge for the work of a coordinator (Figure 6) following the 0 to 5 scale, 0 being the minimum score and 5 the maximum. 
Figure 4. Usual functions of the H\&S coordinator in the execution phase. Source: Self-Elaboration.

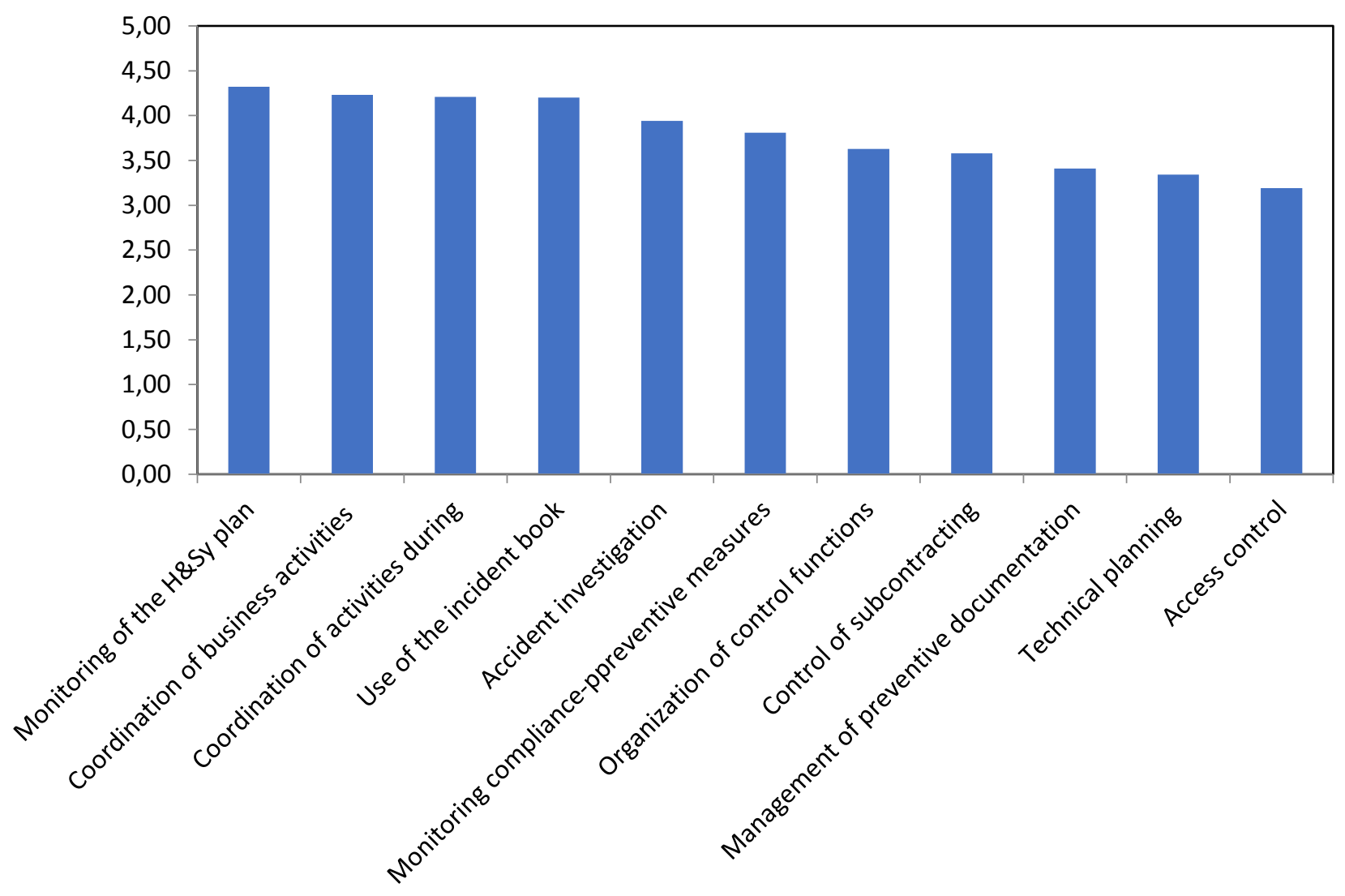

Figure 5. Most-used and most-relevant tools used by H\&S coordinators. Source: Self-Elaboration.

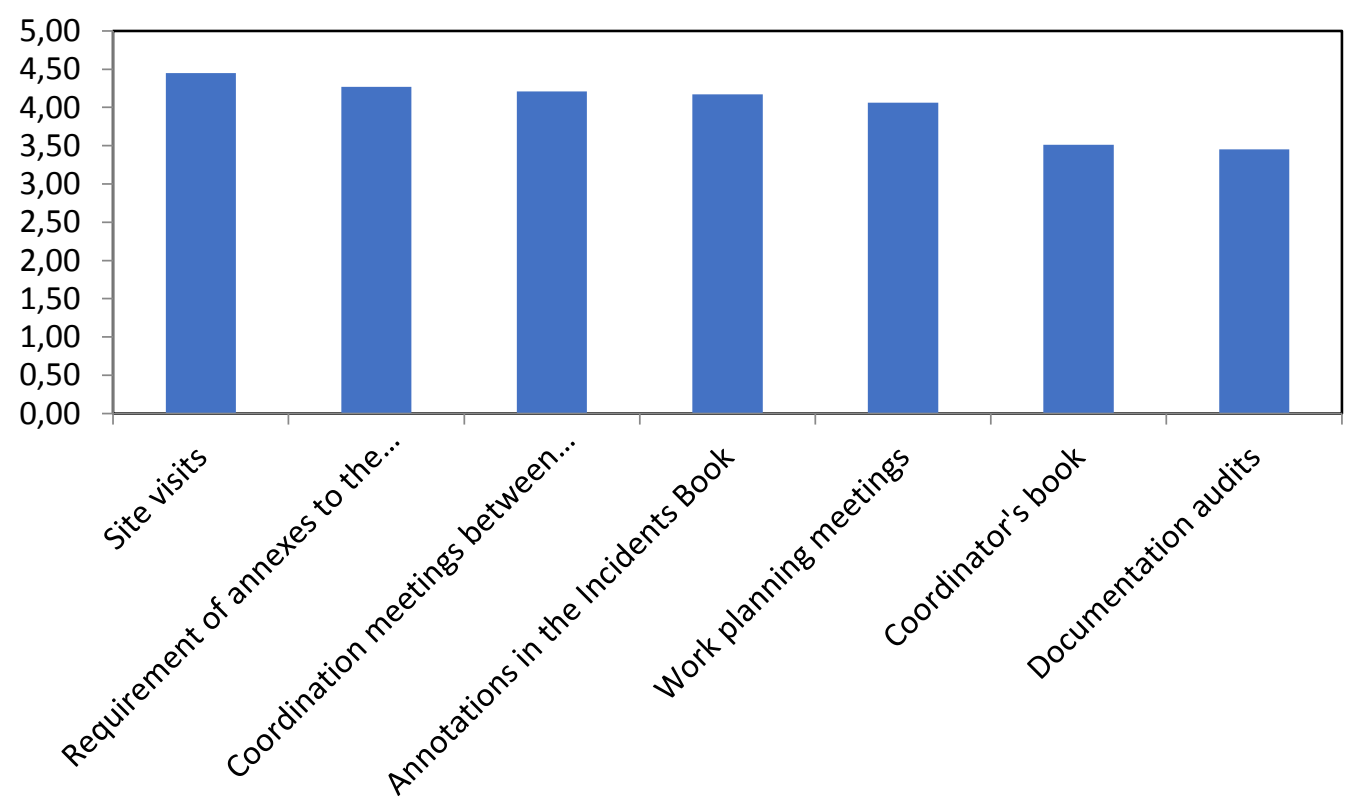




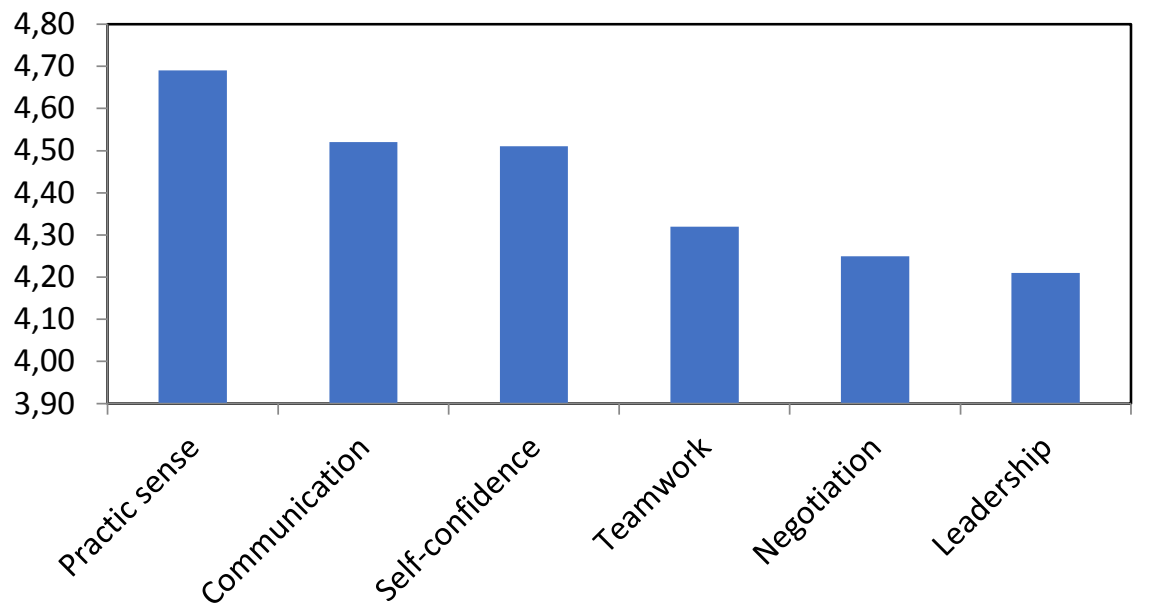

To enhance the validity to this survey these results were shown to an expert panel composed of six people (the technical sub-director of INSHT, two technical specialists of INSHT and IRSST (Regional Institute of Safety and Health at Work), a labor inspector, a technician from a specialized company and a technician of a large engineering company). Several observations were added to the results, validating the general conclusions: academic training for the specific construction work seems unnecessary; the years of experience could be reduced but a higher dedication to the time spent working would be ideal. Finally, they agreed on the main tools, skills and ideal competencies for every health and safety coordinator.

\section{Conclusions}

Despite legal reforms, the construction sector continues to harbor the highest accident incidence rates. As has been demonstrated, studies on the health and safety coordinator in the construction phase of civil engineering projects are nonexistent. Therefore, this article fills a gap in the analysis of the profile, skills, functions and tools of the health and safety coordinator in civil engineering works. Results were examined from three points of view. First, we considered specific documents produced by competent public administrations to know what is being demanded. Next, we analyzed the case of a company specialized in coordination as a useful examination of data collection processes, as well as a determination of tools and profiles. Finally, we assessed the professional coordination sector through a questionnaire for employers of representative health and safety coordination companies in the Spanish case (ECSYS) to discover opinions of interested parties regarding the subjects of this study. We believe this procedure allows reliable conclusions to be drawn that set a trend for the Spanish case and similar countries.

The figure of the health and safety coordinator is perfectly implemented in the construction sector and establishes a relationship with all the agents involved. However, not all these agents are aware of the functions of a health and safety coordinator demanding or imposing "obligations" different from those legally established (RD 1627/97 art 9 in the Spanish case). The conclusions of this study help clarify the obligations of the coordinator, resulting in interest for all stakeholders. The contribution of this study is essential for promoters who must hire their services and define their requested functions. Likewise, knowledge of the functions of a health and safety coordinator will facilitate the performance and success of the tasks and, therefore, reduction of the accident rate.

Based on this rigorous and extensive analysis, recommendations are summarized in Figure 7 as an output of the present research focused on the health and safety coordinator profile, functions, training and main tools. 


\section{Academic training}

- Architect, technical architect, engineer or technical engineer, not strictly necessary according to the specialty of the work

\section{Preventive Training}

- Course of Health and Safety Coordinator as recommended by the National Institute of Safety and Hygiene at Work in its Technical Guide for the Evaluation and Prevention of Risks related to Construction Works

\section{Previous experience}

- Between 3 and 5 years for works of more than 1,000,000 $€$

- Between 1 and 3 years for works between 100,000 and 1,000,000 €

- Less than 1 year for works of up to $€ 100,000$

\section{Required dedication}

- Around $25 \%$ with a weekly work visit for works of up to $€ 100,000$

- Between $25 \%$ and $50 \%$ with a minimum weekly site visit, for works between 100,000 and $1,000,000 €$

- Between $50 \%$ and $100 \%$ with daily visit for works of more than $1,000,000 €$

\section{Main functions}

- Monitoring of the health and safety plan

- Use of incident book

- Coordination of business activities between competing companies

- Coordination of activities during the execution of work so that the principles of preventive action are applied

- Accident investigation

\section{Functions that should not assume}

- Do not include surveillance functions

- Do not include full documentary check functions

\section{Main tools}

- Site visits

- Requirement of annexes to the health and safety plan

- Business coordination meetings

- Annotations in the Incidents Book 
- Include criteria related to the functions of the coordinator in matters of safety and health during the execution of work in the investigation of accidents.

- Promote the creation of tripartite Work Groups (employers-unions-promoters) that actively collaborate with the coordinators in matters of safety and health.

\section{Contracts related with Health and Safety}

- Solvency criteria should be more important based on experience and specialization over economic ones.

- Discard the hiring under the "single objective criterion" of best price and establish economic minimums that respect the corresponding labor agreement, taking as reference a minimum company cost for a coordinator in matters of safety and health at a 100\% dedication of $€ 7,000$ / month

- Encourage the provision of multidisciplinary teams that cover legal aspects and responsibility and ensure the independence of the winning company against the contractor and subcontractor companies in the work.

In the near future, health and safety face new challenges as well as opportunities and synergies related to sustainable construction (e.g., Hinze et al., 2013; Karakhan \& Gambatese, 2017). New technologies such as Building Information Modeling enable virtual construction in design stages so that health and safety can anticipate the execution in the design stage (Arezes et al., 2017).

For future research, a comparable study of the profile, competencies, functions, and tools in the rest of the European Union member states would be possible given similar legislation applied in the region. At the international level, comparing trends in this field (for example, in America and Europe) might support the development of a global standard.

\section{References}

Aires, M.D.M., Gámez, M.C.R. \& Gibb, A. 2010. Prevention through design: The effect of European Directives on construction workplace accidents. Safety Science, 48(2): 248-258.

Arevalo, A, 2003. Seguridad y salud en la construcción. Ingeniería y Territorio 64, 4-9.

Arevalo, C. 2013. Análisis del modelo regulatorio de la seguridad y salud en la construcción en España e integración de la prevención a través del diseño. PhD Thesis. Universidad Politécnica de Madrid. ETSICCP. Madrid.

Arezes, P., Baptista, J.S., Barroso, M., Carneiro, P., Cordeiro, P., Costa, N., Melo, R.B., Miguel, A.S. \& Perestrelo, G. 2017. Occupational Safety and Hygiene V. CRC Press, Taylor \& Francis Group. London, UK.

CNSST. 2001. Grupo de Trabajo Construcción. Ponencia General. Comisión Nacional de Seguridad y Salud en el Trabajo. http://www.insht.es/InshtWeb/Contenidos/Instituto/Comision/GruposTrabajo/ponencia.pdf

Edwards, D.J. \& Holt, G.D. 2014. Antecedents of Health and Safety Issues related to Plant Trailer Wheels. Journal of Construction Engineering and Management, 140(7), 04014027.

Esteban, J. 2011. Estudio sobre la integración de la prevención en la fase de redacción de los proyectos. PhD Thesis. Universidad Politécnica de Madrid, Madrid.

Esteban, J., Ros, A., Sanz, M. \& Lozano, R.V. 2013. La integración de la prevención en la fase de diseño. El papel del proyectista en España y en los países de la Europa de los 15. Informes de la Construcción, 65(532): 545.

Eurostat. 2016. Accidents at work statistics. http://ec.europa.eu/eurostat/statistics-explained/index.php/Accidents_at_work_statistics

Fuentes del Burgo, J. \& Navarro-Astor, E. 2013a. Barriers to training: the case of building engineers working as site managers in construction SMEs. 17th International Congress in Project Management and Engineering. Logroño 17-19th July.

Fuentes del Burgo, J. \& Navarro-Astor, E. 2013b. La formación del ingeniero de edificación en empresas constructoras en la Comunidad de Castilla La Mancha. Su influencia en la satisfacción laboral. Intangible Capital, 9(3), 590-643. 
Garcia, F. 2011. Los sujetos activos de los delitos contra la seguridad y salud en el trabajo. Especial consideración al sector de la construcción. Tesis Doctoral. Universidad Carlos III de Madrid, Madrid.

Hinze, J., Godfrey, R. \& Sullivan, J. 2013 (June). Integration of Construction Worker Safety and Health in Assessment of Sustainable Construction. Journal of Construction Engineering and Management, 139(6), 594.

https://ascelibrary.org/doi/full/10.1061/\%28ASCE\%29C0.1943-7862.0000651

INSSHT. 2010. Actividades económicas con mayor siniestralidad, penosidad y peligrosidad: Sector de la construcción. Estudio sobre el perfil demográfico, siniestralidad y condiciones de trabajo. Instituto Nacional de Seguridad e Higiene en el Trabajo. Madrid. https://www.insst.es/documents/94886/96076/Actividades+econ\%C3\%B3micas+con+mayor+siniestralidad\%2C+penosidad\%2C+y+peligrosida d+Sector+del+transporte+terrestre/f08109b2-309c-4a0b-91cd-992885267104

Karakahn, A.A. \& Gambatese, J.A. 2017. Integrating Worker Health and Safety into Sustainable Design and Construction: Designer and Constructor Perspectives. Journal of Construction Engineering and Management, 143(9).

Koehn, E.E. \& Datta, N.K. 2003. Quality, Environmental, and Health and Safety Management Systems for Construction Engineering. Journal of Construction Engineering and Management, 129(5).

Lopez-Arquillos, A. \& Rubio-Romero, J. 2015. Proposed Indicators of Prevention Through Design in Construction Projects. Revista de la Construcción $14(2), 58-64$.

Lozano, R.V. 2015. Optimización de la figura del técnico coordinador de seguridad y salud en obras de edificación. Tesis doctoral. Universidad Politécnica de Madrid. ETSE. Madrid.

Maiti, S. \& Choi, J. 2019. An evidence-based approach to health and safety management in megaprojects. International Journal of Construction Management. Published online. https://www.tandfonline.com/doi/full/10.1080/15623599.2019.1602580

Mishra, A.K., Lama, C., Sah, D.P., Badagha, D.G. 2019. Effectiveness of Safety Measures Implementation. Journal of Advanced Research in Civil Engineering and Environmental Engineering, 6(2), 1-20.

Ros, A., Ortiz, I., Palomo, J.G. \& Uruburu, A. 2012. A proposal for improving safety in construction projects by strengthening coordinators' competencies in health and safety issues. Safety Science, 54, 92-103. http://oa.upm.es/15373/1/INVE_MEM_2012_126736.pdf

Ros, A. 2013. Modelo para la certificación del coordinador en materia de seguridad y salud basado en sus competencias. Tesis doctoral Universidad Politécnica de Madrid. E.U. de Arquitectura Técnica. Madrid.

Vicente, M.A. 2008. El coordinador de seguridad y salud en la ejecución de las obras de construcción: obligaciones y responsabilidades. Revista de estudios Jurídicos, 9, 1-4. https://revistaselectronicas.ujaen.es/index.php/rej/article/download/113/101/

Vedsmand, L. 2011. New elements of coordinators' training, competencies and skills. Second European conference on health and safety coordination in the construction industry. Madrid, Spain. 